\title{
Green Electrochemistry - A Versatile Tool in Green Synthesis: an Overview
}

\author{
Susai Rajendran, ${ }^{a,}$ R. Joseph Rathish, ${ }^{b}$ S. Santhana Prabha, ${ }^{b}$ A. Anandan ${ }^{c}$ \\ ${ }^{a}$ Research Centre, Department of Chemistry, RVS School of Engineering and Technology, \\ Dindigul - 624 005, Tamilnadu, India \\ ${ }^{b}$ PSNA College of Engineering and Technology, Dindigul, India \\ ${ }^{c}$ SKV Higher Secondary School, Kandampalayam-637201, India
}

Received July 15, 2016; accepted September 06, 2016

\begin{abstract}
Green is attractive and beautiful. Green chemistry has attracted scientists and researchers from various fields. Electrolysis is considered as green electrochemistry, because electrochemical process can be stopped and controlled at any time and at any stage of the reaction. Usually water is used as the solvent. Corrosive acids are not used. Toxic chemicals are not involved. The main components of an electrolysis process are anode, cathode and electrolyte. By using suitable anodes, cathodes and medium, electrolysis has been applied in various fields. Electrolysis has been used to decolourise dyes from effluents of textile industries. The decolourisation efficiencies of various anodes, such as platinised-titanium, mild steel and aluminium in various electrolytic media, such as well water and sea water, have been evaluated and compared. The role of positive chlorine in the decolourisation process has been established. Electrolysis, in presence of a suitable reducing agent, has also been used to synthesize nanoparticles. Copper nanoparticles and silver nanoparticles have been produced by making use of reducing agents, such as sodium potassium tartrate and trisodium citrate. Various plants extracts have also been used as reducing agents. The nanoparticles synthesized by green methods have been characterized by UV-Visible absorption spectroscopy and fluorescence spectroscopy. The surface morphology of these nanoparticles has been characterized by SEM and EDS. Blue pigment that can be used in paint industry has been synthesized by green electrolysis. For this purpose, waste mild steel rod has been used, and graphite has been used as anode. The blue pigment prepared has been characterized by UV-Visible absorption spectroscopy and fluorescence spectroscopy. The surface morphology of these nanoparticles has been characterized by SEM and EDS. The blue pigment prepared is found to be in the nano range. This can be used in paint industry and also in the field of nano biosensors. By green electrolysis method, Hofmann rearrangement has been successfully effected, benzamide being the starting material. The product obtained has been diazotised and coupled with $\alpha$-napthol and $\beta$-napthol to give dyes. The dyes have been characterized by UV-Visible absorption spectroscopy and fluorescence spectroscopy. Polyaniline has also been synthesized by green electrolysis process, without using expensive oxidizing agents, but using positive chloride ions generated in-situ during electrolysis, in the presence of sodium chloride solution as electrolyte. The polyaniline produced has been characterized by UV-Visible absorption spectroscopy, fluorescence spectroscopy and FTIR spectra.
\end{abstract}

Keywords: Green chemistry, green electrochemistry, green synthesis, nanoparticles, blue pigment, decolourisation, Hoffman rearrangement, polyaniline.

\footnotetext{
* Corresponding author. E-mail address: suasirajendran@gmail.com
} 


\section{Introduction}

Electrochemistry deals with chemical changes brought out by electricity, and electricity generated by chemical changes. Electron is the king of Electrochemistry. It rules electrochemistry. Electricity is generated, and chemical reactions take place, due to the movement of electrons from one source to another. Electron generation occurs at one place; the electron moves through a medium, and reaches a particular site. The electron is generated at the anode and it moves through the electrical circuit outside the solution system. It enters the solution system through the cathode and travels towards the anode through a medium which is called an electrolyte (Fig. 1).

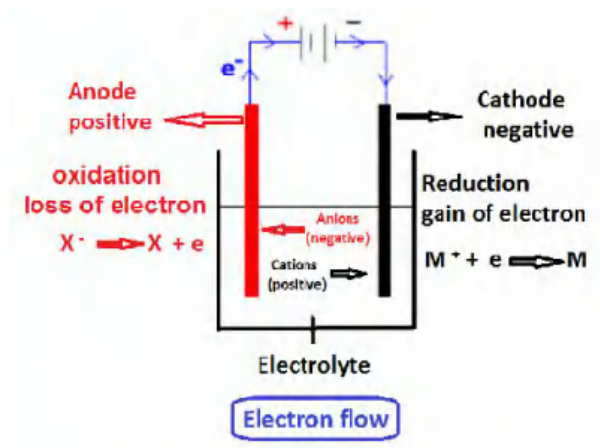

Figure 1. Electron flow in electrolysis.

During this process many chemical reactions take place. The important components of this process are a source of AC electricity, a rectifier to produce DC current, an anode, a cathode and an electrolyte solution. An ammeter is connected in series, and a voltmeter in parallel. This experimental setup can be used for a process called electrolysis (Fig. 2).

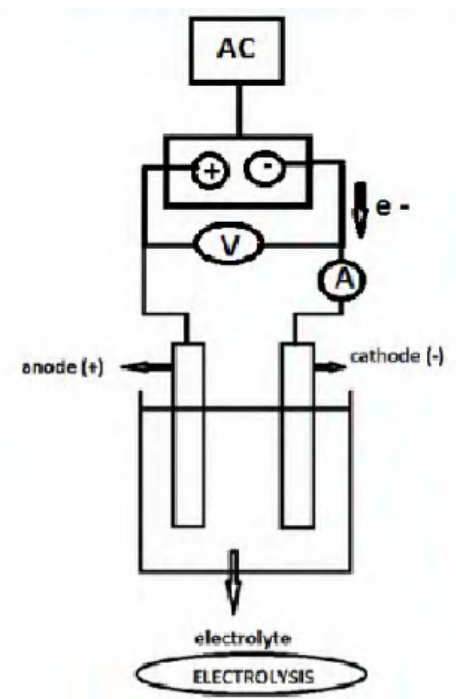

Figure 2. Block diagram for electrolysis.

By selecting a variety of anodes, cathodes, electrolytic medium, solvent, potential difference (volt) and current density, many wonders can be done in the undivided cell. When an aqueous solution of sodium chloride is electrolyzed, $\mathrm{Cl}^{+}$ is generated at anode [1]. Various other species are also produced as per the 
views of many other scientists. $\mathrm{Cl}+$ can be used to bring about variety of chemical reactions.

Dyes from textile effluents can be removed by chemical method [2], bio chemical method [3] and electrochemical method [4].

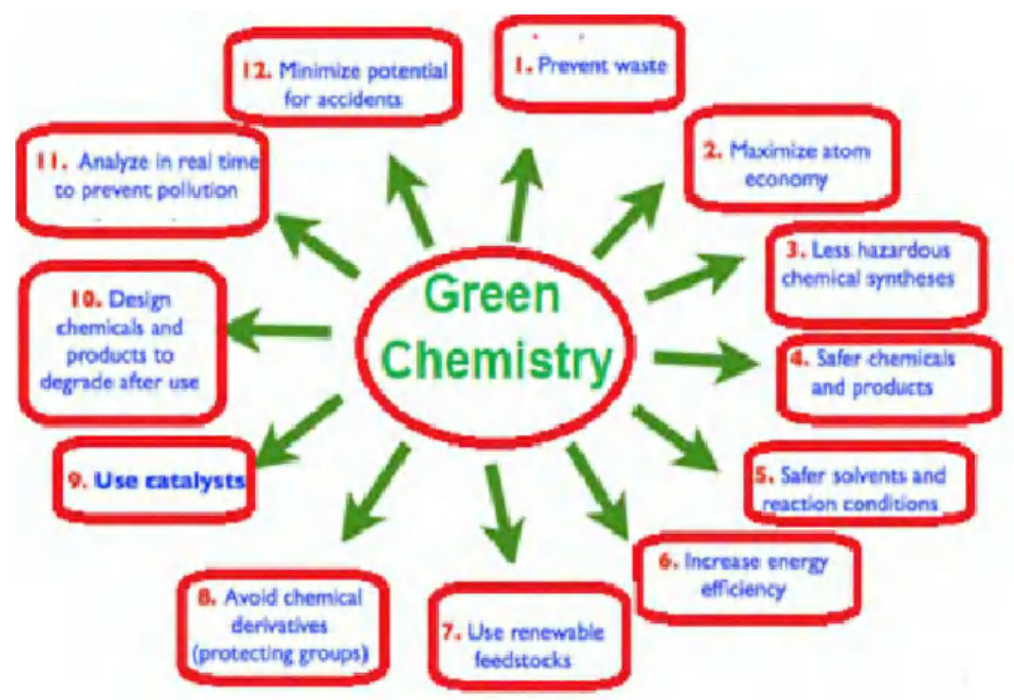

Figure 3. 12 Principles of green chemistry.

Nano particles can be generated by various methods, by reducing the particular metal ions, by using suitable reducing agents and capping agents [5].Hofmann rearrangement has been conventionally effected by making use of acid amides and hypo halites to produce primary amines [6]. Polyaniline has been produced from aniline, by making use of a variety of oxidizing agents [7].

In the old days our environment was healthy and safe, because there was less industrialization, and there was no deforestation, but rather continuous forestation. Because of the development of science and technology and the greediness of mankind, our environment has been polluted. To protect the nature, principles of green chemistry have been formulated (Figs. 3 and 4).

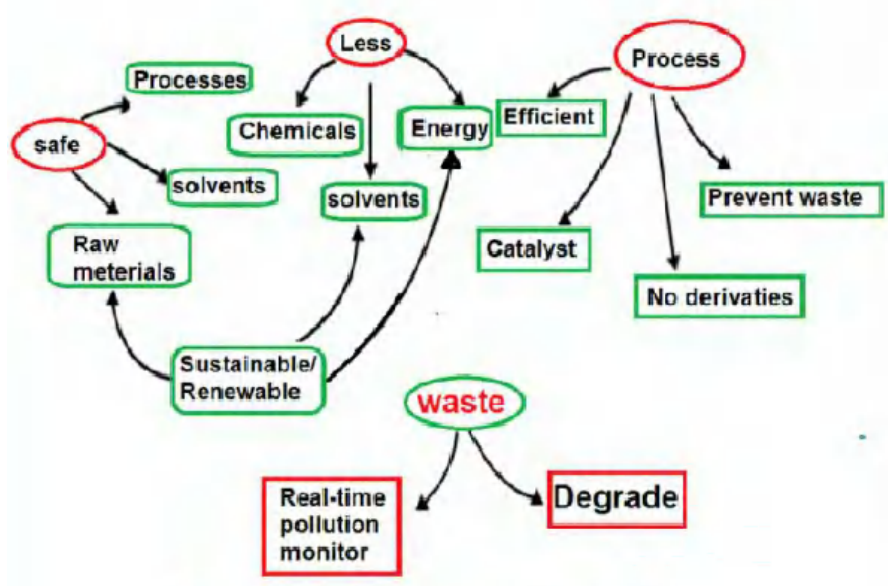

Principles of Green Chemistry

Figure 4. Concepts of green chemistry. 
These principles emphasize that safe processes, raw materials and solvents must be used.

The use of solvents, energy and chemicals must be lesser. Any green process should be efficient, prevent waste and make use of catalysts. Raw materials, solvents and energy should be sustainable and renewable.

The present work is undertaken to employ green electrolysis processes in the following events:

- Decolourisation of dyes;

- Production of a blue pigment from waste rusted iron rods;

- Electrochemical synthesis of silver nano particles and copper nano particles;

- To effect Hofmann rearrangement, there was an electrochemical start from benzamide and dyes were produced from the product obtained from electrolysis ;

- To produce poly aniline electrochemically $\mathrm{Cl}^{+}$was used as oxidizing agent.

In all the cases water is used as solvent; non toxic chemicals are used; less expensive reagents are used. Ordinary sodium chloride, even commercial sodium chloride, can be used to produce $\mathrm{Cl}^{+}$, which acts as a wonderful oxidizing agent. Apart from platinised titanium anode, other less expensive electrodes such as aluminium, mild steel, graphite, copper and silver are used. This process is an electrochemical process. Hence, the reaction can be started and stopped at will. No hazardous side products are produced. The environments are very safe. Wealth is produced even from waste materials such as waste iron rods. Natural product extracts have been used, in some cases as reducing agents, as in the case of production of silver nano particles, by reducing the silver ions produced electrochemically/chemically by neem extract.

\section{Experimental}

\section{Electrolysis}

Electrolysis was carried out in an undivided cell. Graphite was used as cathode. The anode was platinised titanium or aluminium or mild steel or copper. The solvent was water (well water) or double distilled water or sea water. In some cases sodium chloride was also added. For synthesis of nano particles double distilled water was used and the chemicals were very pure. For other cases, chemicals readily available were used. The following experiments were carried out:

- Electrochemical decolourisation of dyes;

- Electrochemical synthesis of blue pigment;

- Electrochemical synthesis of silver nano particles and copper nano particles;

- Electrochemical Hofmann rearrangement;

- Electrochemical synthesis of poly aniline.

\section{Results and discussion}

In this section, the following are discussed: 
- Electrochemical decolourisation of dyes;

- Electrochemical synthesis of blue pigment;

- Electrochemical synthesis of silver nano particles and copper nano particles;

- Electrochemical Hofmann rearrangement;

- Electrochemical synthesis of poly aniline.

\section{Electrochemical decolourisation of dye}

A blue dye "Blue ARDE dye" used in dyeing industry has been decolourised in the present study. An aqueous solution of this dye (2\%) has been used in this electrolysis process. Graphite was used as cathode, mild steel or platinised titanium were used as anode. Sodium chloride solution was used as electrolyte. When the dye solution was electrolysed, decolourisation took place effectively (Fig. 5). Optical densities were measured before and after decolourisation. Decolourisation efficiency (DE) was calculated using the equation:

$$
\mathrm{DE}=\left[\left(\mathrm{OD}_{1}-\mathrm{OD}_{2}\right) / \mathrm{OD}_{1}\right] \times 100 \%
$$

where $\mathrm{OD}_{1}$ and $\mathrm{OD}_{2}$ are optical densities before and after decolourisation, respectively.

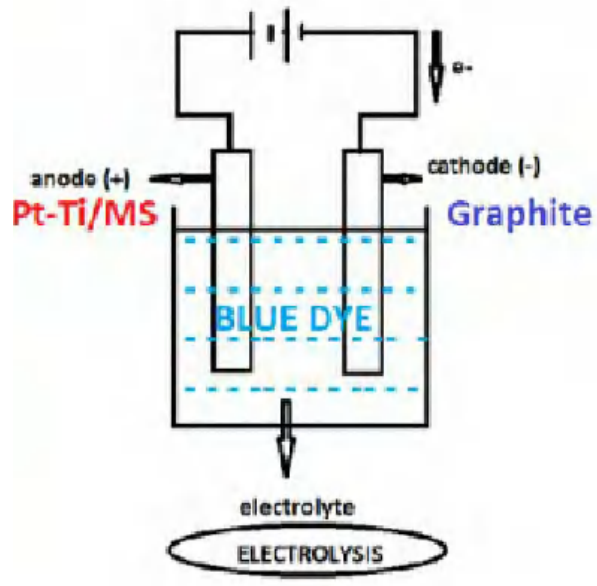

Figure 5. Decolourization of blue dye.

The results are given in Table 1.

It is observed that platinised titanium offered better decolourisation efficiency than mild steel. As the concentration of sodium chloride increases, DE also increases, because in presence of higher concentration of $\mathrm{NaCl}$, more $\mathrm{Cl}^{+}$is produced and hence, more dye molecules were decolourised. For a given concentration of sodium chloride, as the applied voltage increases, DE also increases, since the flow of electrons increases as the potential difference increases. For a given concentration of $\mathrm{NaCl}$ and a given voltage, platinised titanium offered better DE than mild steel. 


\section{Mechanism of decolourisation}

When sodium chloride solution is electrolyzed, positive chloride $\left(\mathrm{Cl}^{+}\right)$is produced [1]. This converts coloured compounds into colourless products (Fig. $6)$.

Table 1. Decolourization of blue dye.

Decolourisation of Blue ARDE dye OD $1=0.999$

\begin{tabular}{|c|c|c|c|c|c|}
\hline Anode & $\begin{array}{c}\text { Poti. } \\
v\end{array}$ & 002 & $\begin{array}{l}\mathrm{OE} \\
\times\end{array}$ & $\begin{array}{c}\mathrm{NaCl}, \\
\text { E }\end{array}$ & $\begin{array}{l}\text { Current density, } \\
\qquad \mathrm{mA} / \mathrm{cm}^{2}\end{array}$ \\
\hline MS & 6 & 0.233 & 77 & 5 & 50 \\
\hline MS & 6 & 0.149 & B5 & 10 & 52 \\
\hline ms & 6 & D. 099 & 90 & 15 & 54 \\
\hline MS & 6 & 0.049 & 95 & 20 & 56 \\
\hline MS & 4 & 0.139 & 86 & 20 & 50 \\
\hline $\mathrm{Pt}-\mathrm{TI}$ & 6 & 0.002 & 99.8 & 10 & 53 \\
\hline $\mathrm{Pt}-\mathrm{TI}$ & 6 & 0.149 & 85 & 5 & 48 \\
\hline$P t=\pi$ & 4 & 0.179 & 82 & 10 & 50 \\
\hline
\end{tabular}
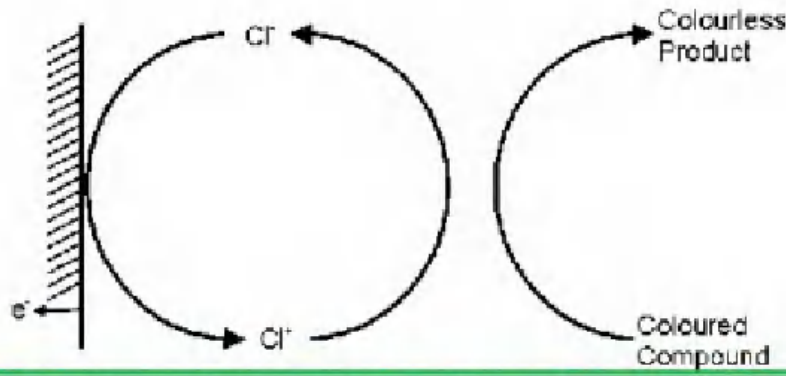

Mechanism of decolourisation of a dye solution by Positive Chloride Ion generated in-situ by Green Electrolysis

Figure 6. Mechanism of decolourisation.

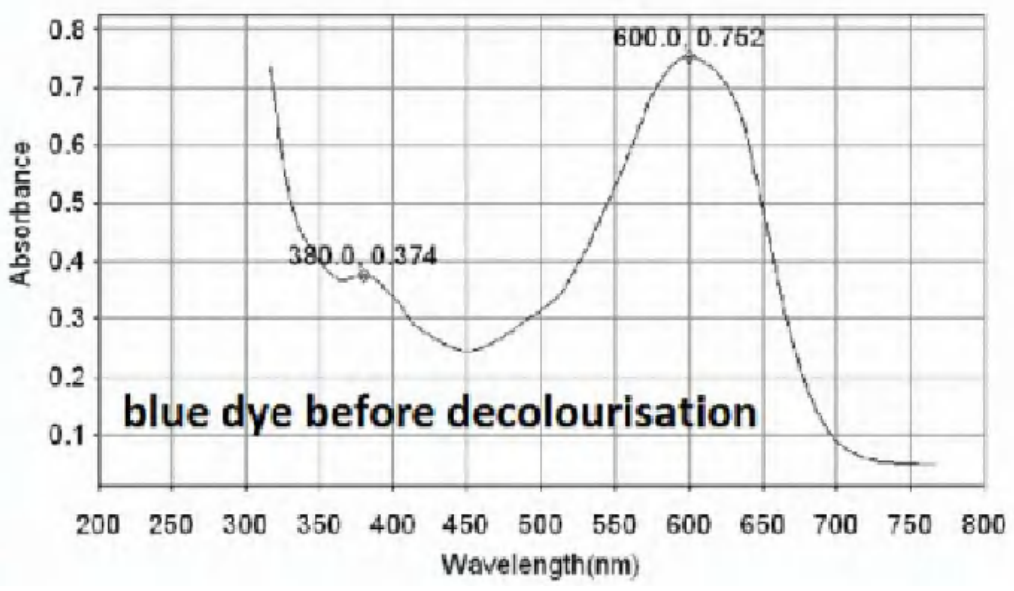

Figure 7. Blue dye before decolourisation.

\section{$U V$-visible absorption spectra}

The UV-visible absorption spectra of dye solution before and after decolourisation are shown in Figs. 7, 8 and 9. 
In Fig. 7 the absorption in the $300 \mathrm{~nm}$ region is due to $\pi-\pi^{*}$ electronic transition of the aromatic ring of the dyes. The peak at $600 \mathrm{~nm}$ is due to the chromophore group on the dye.

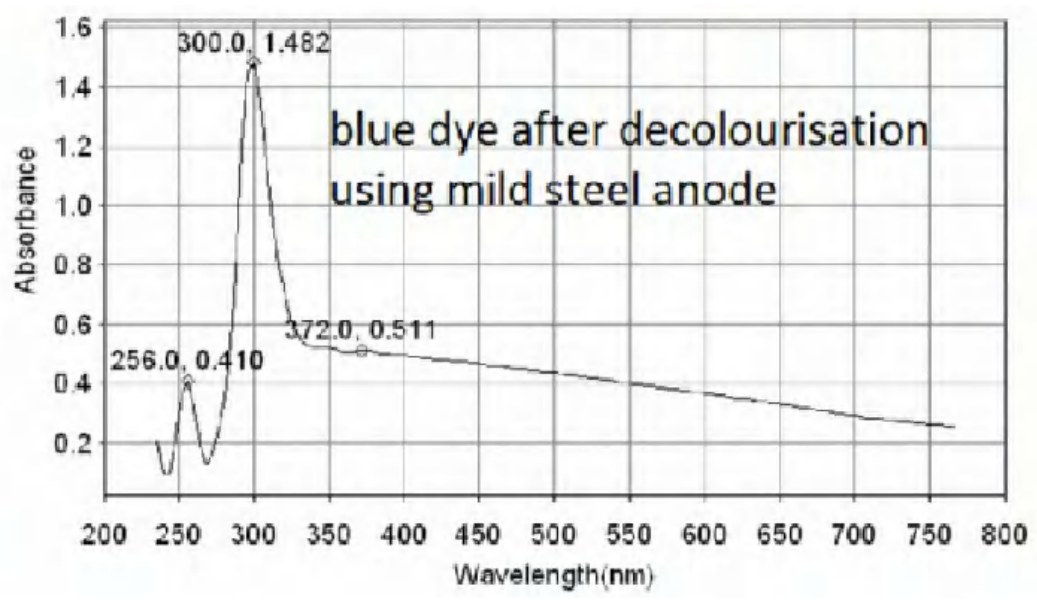

Figure 8. Blue dye after decolourisation using mild steel anode.

From Fig. 8 it is observed that when mild steel is used as anode, the chromophore has completely disappeared. The peak corresponding to aromatic rings is present. When platinised titanium is used as anode (Fig. 9), the aromatic rings and the chromophore are still present, but the intensity has decreased. The decolourisation efficiency is very high $(99.8 \%)$. Based on the same principles, several dyes such as methyl orange [8], eriochrome black T [9], and orange $3 \mathrm{R}$ dye [10] have been decolourised.

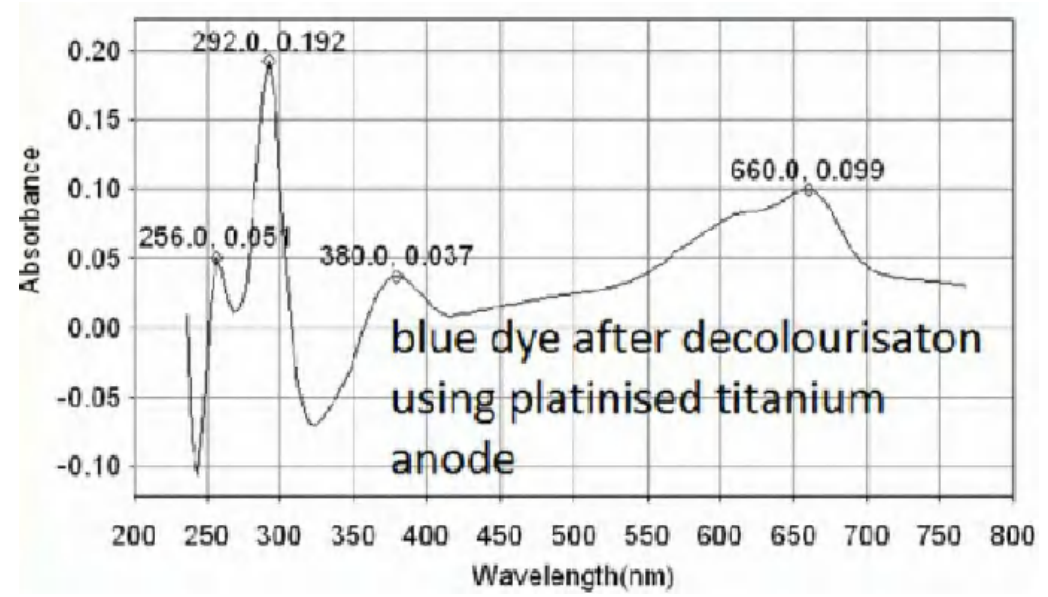

Figure 9. Blue dye after decolourisation using Pt-Ti anode.

\section{Synthesis of blue pigment (Prussian blue) from waste rusted mild steel Electrolysis}

$1 \mathrm{~g}$ of potassium ferrocyanide was dissolved in $10 \mathrm{~mL}$ of water in an undivided cell. $5 \mathrm{~g}$ of $\mathrm{NaCl}$ were added. A rusted mild steel was pickled and cleaned with water. It was used as anode. Graphite was used as cathode. A potential of 6 volts was applied for 5 minutes. Current density was $250 \mathrm{~mA} / \mathrm{cm}^{2}$. The solution turned blue due to the formation of Prussian blue (Fig. 10). 


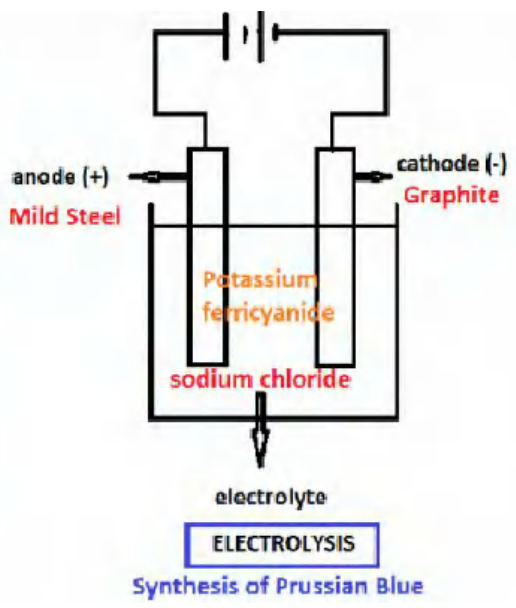

Figure 10. Electrochemical synthesis of Prussian blue.

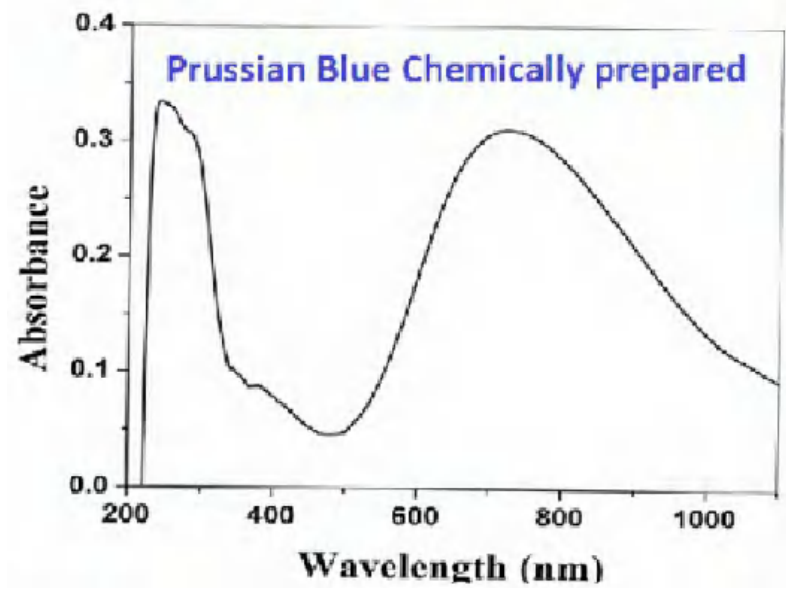

Figure 11. UV-visible adsorption spectrum of Prussian blue chemically prepared.

\section{$U$ V-visible absorption spectra}

The UV-visible absorption spectrum of prussian blue (PB) prepared by chemical method (by mixing aqueous solutions of potassium ferricyanide and ferrous sulphate) is shown in Fig. 11. Peaks appeared at $275 \mathrm{~nm}$ and $750 \mathrm{~nm}$.

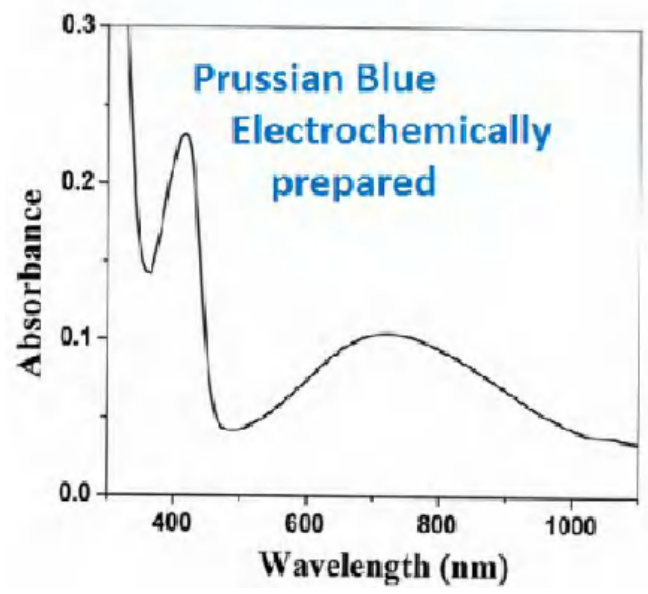

Figure 12. UV-visible adsorption spectrum of electrochemically prepared Prussian blue. 
It is observed (Fig. 12) that the UV-visible absorption spectrum of prepared electrochemically PB matches with that prepared chemically. Thus, the formation of PB by electrochemical method from mild steel is confirmed.

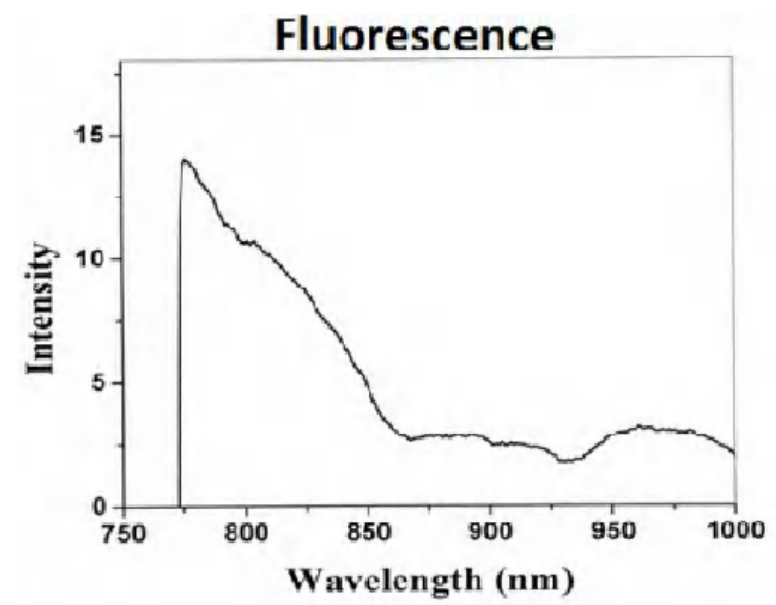

Figure 13. Emission spectrum of Prussian blue (chemical method).

\section{Fluorescence spectra}

The fluorescence spectra $(\lambda \mathrm{ex}=750 \mathrm{~nm})$ of chemically and electrochemically prepared PB are shown in Figs. 13 and 14. They closely resemble. Thus, formation of $\mathrm{PB}$ is confirmed.

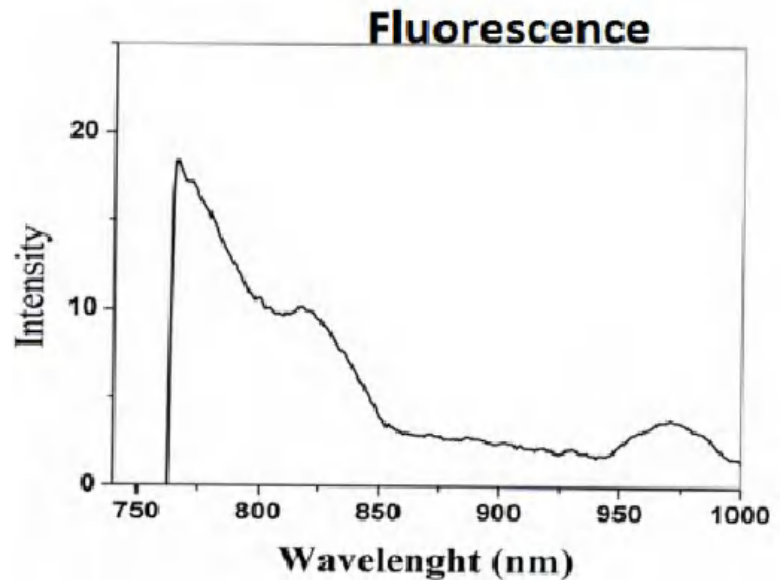

Figure 14. Emission spectrum of Prussian blue (electrochemical method).

\section{FTIR spectra}

The structures of Prussian blue are shown in Figs. 15 and 16.

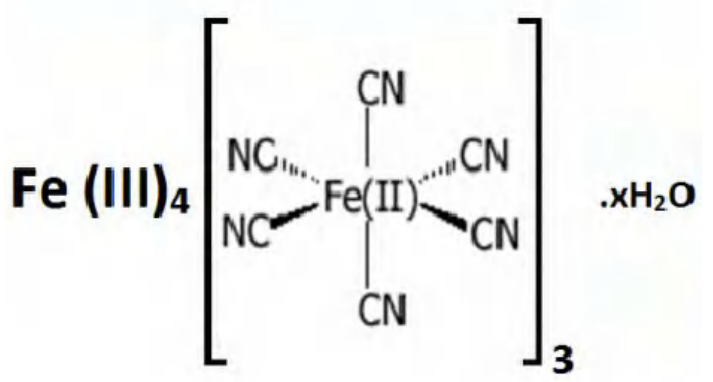

Figure 15. Structure of Prussian blue. 


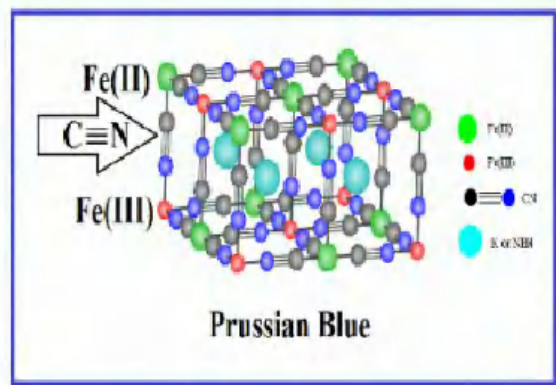

Figure 16. Crystal structure of Prussian blue.

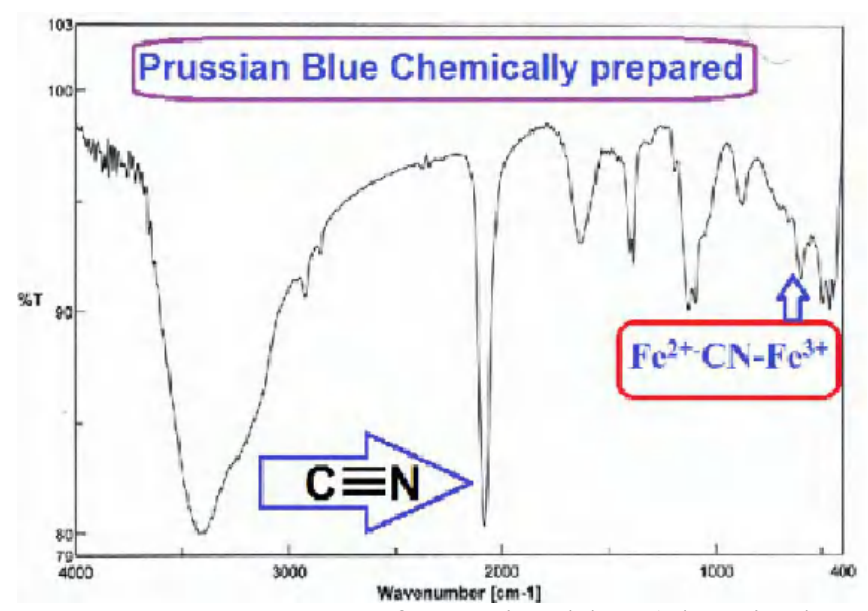

Figure 17. FTIR spectrum of Prussian blue (chemical method).

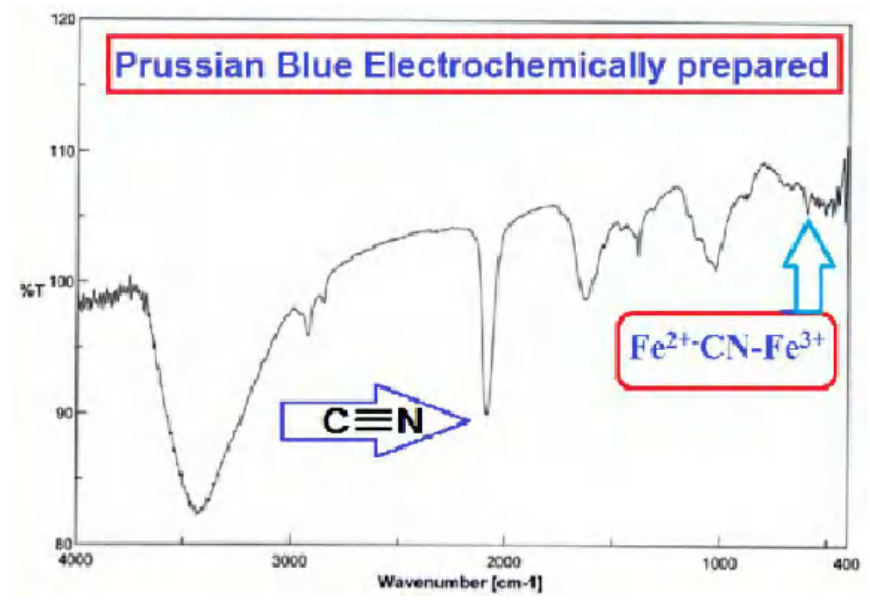

Figure 18. FTIR spectrum of Prussian blue (electrochemical method).

FTIR spectra of chemically and electrochemically prepared PB are shown in Figs. 17 and 18.

The presence of $\mathrm{C} \equiv \mathrm{N}$ peak and $\mathrm{Fe}^{2+}-\mathrm{CN}-\mathrm{Fe}^{3+}$ peak confirmed the formation of PB from mild steel.

\section{SEM images}

SEM images of chemically and electrochemically prepared PB are shown in Figs. 19 and 20. Squares and pentagons are seen. Some triangles are also seen. 


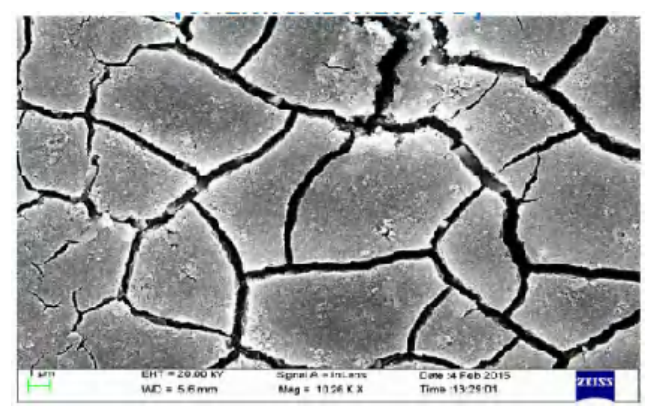

Figure 19. SEM image of Prussian blue (chemical method).

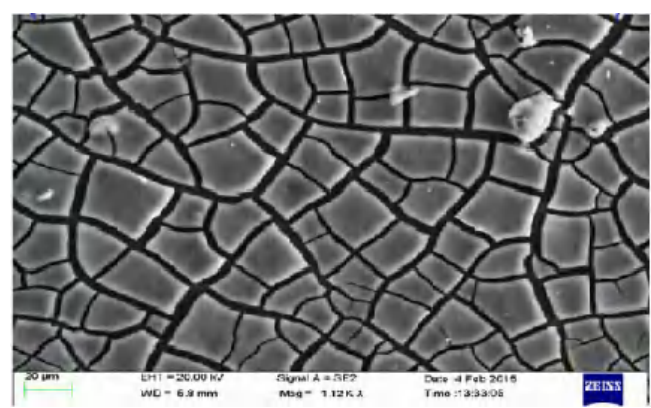

Figure 20. SEM image of Prussian blue (electrochemical method).

\section{Size of Prussian blue (PB) nano particles}

The sizes of the PB nano particles prepared by chemical method are found to be $41.19 \mathrm{~nm}, 52.95 \mathrm{~nm}$ and $55.90 \mathrm{~nm}$ (Fig. 21).

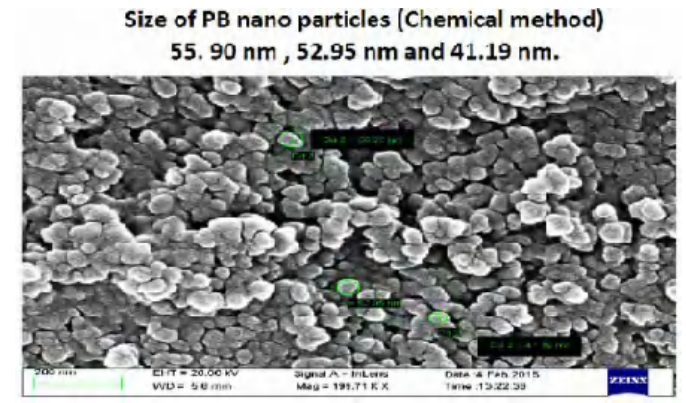

Figure 21. Size of PB nano particles (chemical method).

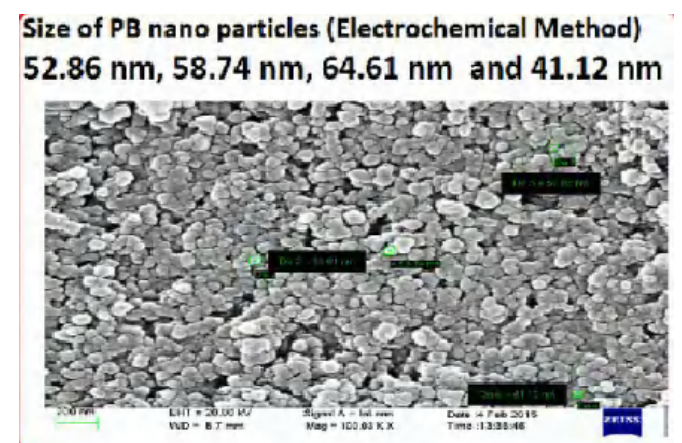

Figure 22. Size of PB nano particles (electrochemical method).

The sizes of the PB nano particles prepared by electrochemical method are found to be $41.12 \mathrm{~nm}, 52.86 \mathrm{~nm}, 58.74 \mathrm{~nm}$ and $64.61 \mathrm{~nm}$ (Fig. 22). 


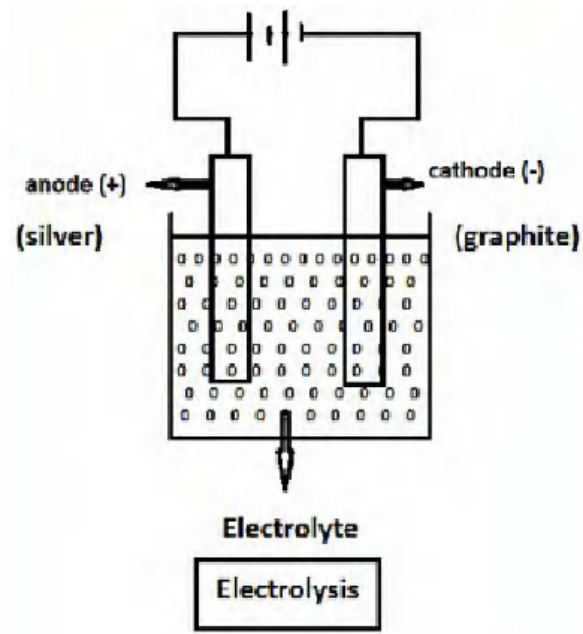

Figure 23. Electrochemical synthesis of AgNPs.

\section{Synthesis of silver nano particles}

Silver nano particles have been prepared by electrolysis method (Fig. 23). Pure silver rod was used as anode. Graphite was used as cathode. The electrolyte (reducing agent) was sodium potassium tartrate (SPT) and polyvinyl alcohol. When a potential of 6 volts was applied for 5 minutes (current density 50 $\mathrm{mA} / \mathrm{cm}^{2}$ ), silver ions were released, which were reduced by SPT.

$\mathrm{Ag}^{+}+\mathrm{SPT} \rightarrow \mathrm{Ag}$

The UV-visible absorption spectrum is shown in Figs. 24 and 25.

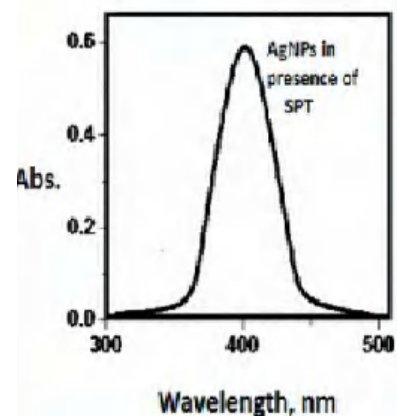

Figure 24. UV- visible adsorption spectrum of AgNPs (using SPT).

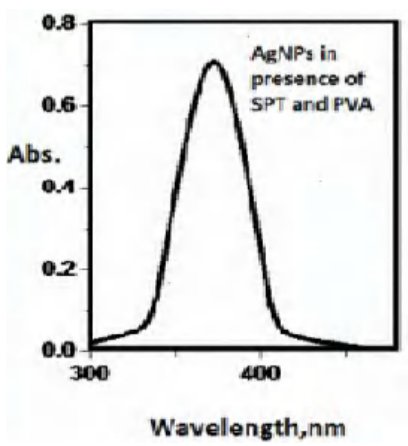

Figure 25. UV- visible adsorption spectrum of AgNPs (SPT and PVA). 


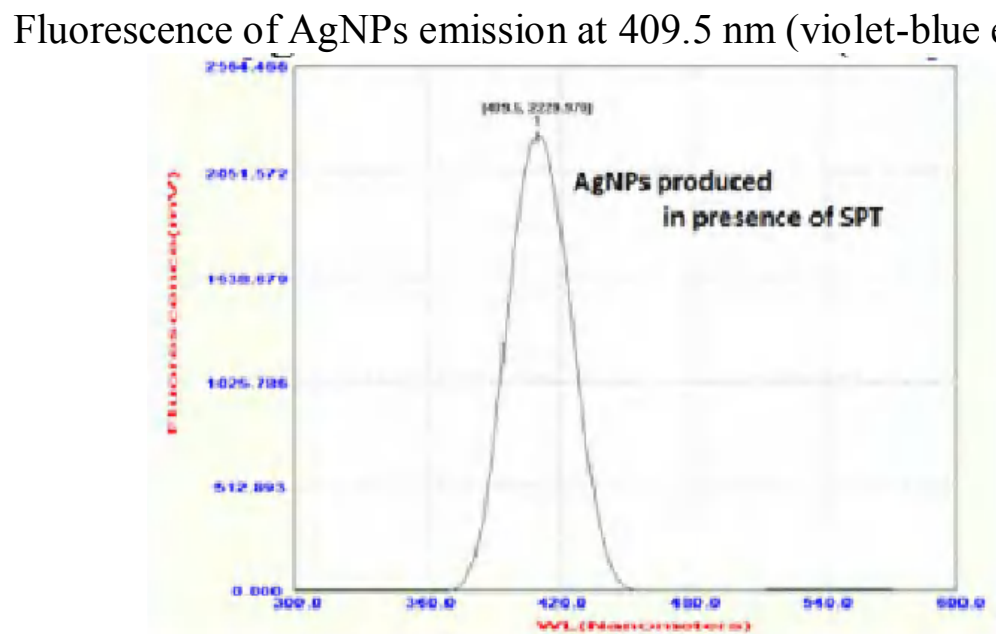

Figure 26. Emission spectrum of AgNPs (SPT system).

Peaks around $400 \mathrm{~nm}$ are due to AgNPs. They are found to be UV-fluorescence $\left(\lambda_{\text {ex }}=400 \mathrm{~nm}\right)$ (Figs. 26 and 27).

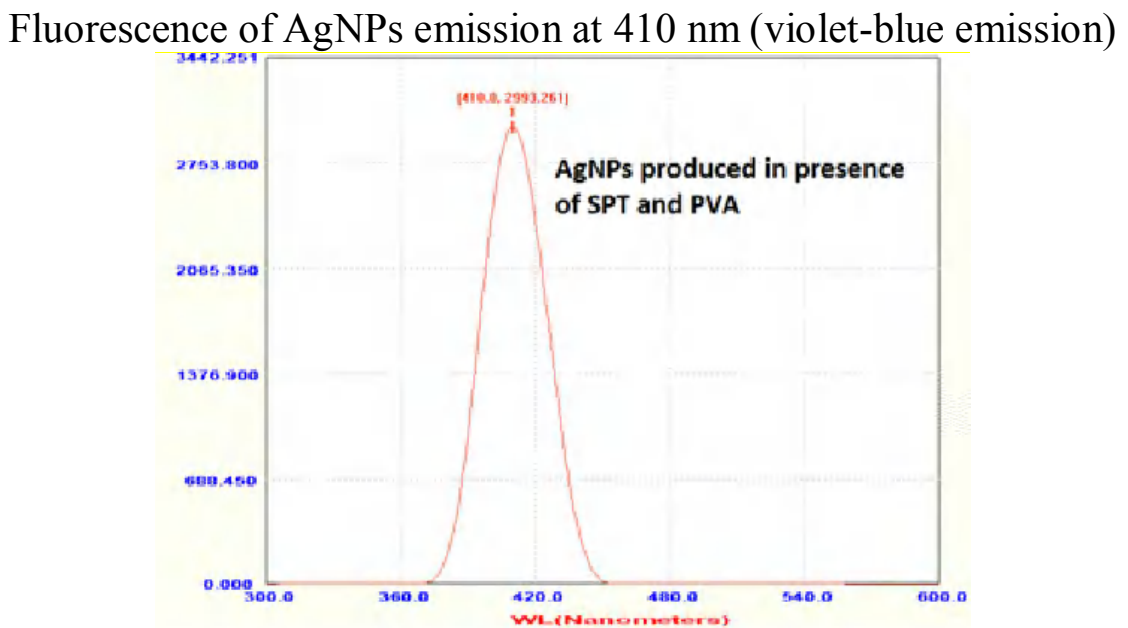

Figure 27. Emission spectrum of AgNPs (SPT + PVA system).

The sizes of AgNPs are found to be in the range of 75 to $100 \mathrm{~nm}$ (Fig. 28). AgNPs are found to be spherical. Some flowers of AgNPs are also seen (Fig.28).

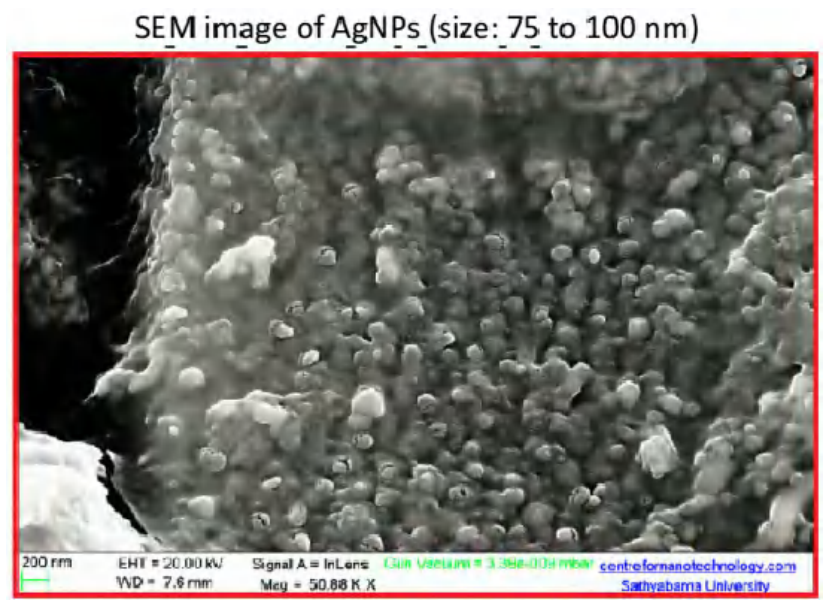

Figure 28. Size and shape of AgNPs. 


\section{EDAX spectrum}

The EDAX spectrum confirms the presence of silver (Fig. 29).

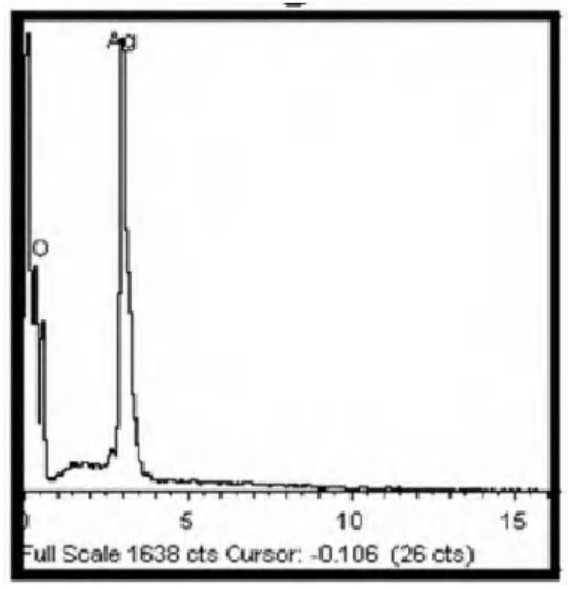

Figure 29. EDAX spectrum of AgNPs.

\section{Formation of copper nanoparticles}

In the electrolysis process, copper rod was used as anode. Graphite was used as cathode. The electrolyte was $1 \%$ of trisodium citrate (TSC) / sodium potassium tartrate (SPT). A potential difference of 6 volts was applied for 5 minutes. The current density was $50 \mathrm{~mA} / \mathrm{cm}^{2}$.

The copper ions produced at anode were reduced by reducing agents such as SPT and TSC (Fig. 30).

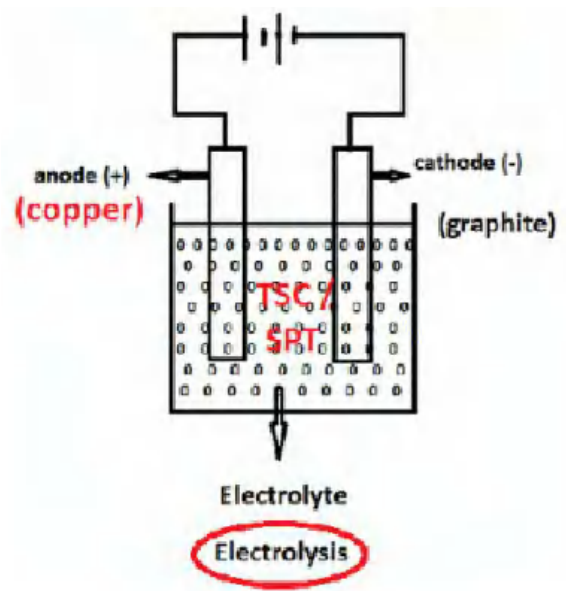

Figure 30. Electrochemical synthesis of copper nano particles.

When TSC is used as reducing agent, the CuNPs show peaks at $228 \mathrm{~nm}, 275 \mathrm{~nm}$ and $681 \mathrm{~nm}$ in the UV-visible absorption spectrum (Fig. 31).

When SPT is used as reducing agent, peaks appear at $224 \mathrm{~nm}, 256 \mathrm{~nm}$ and 691 nm (Fig. 32). 


\section{Copper nano particles: TSC system}
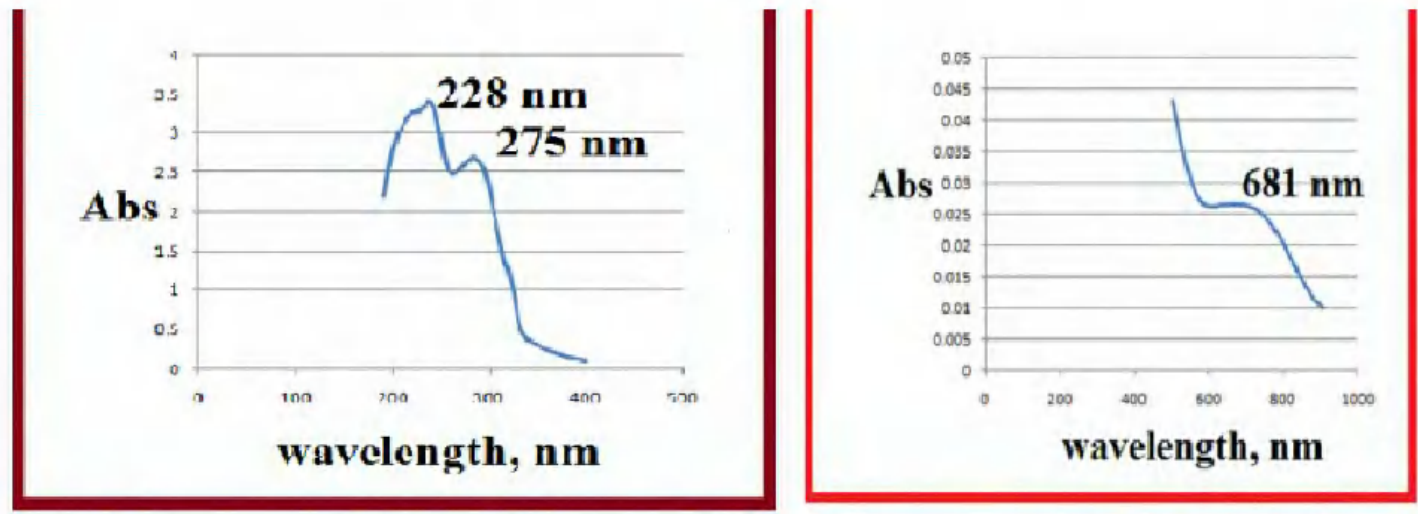

Figure 31. UV-visible absorption spectrum of copper NPs.
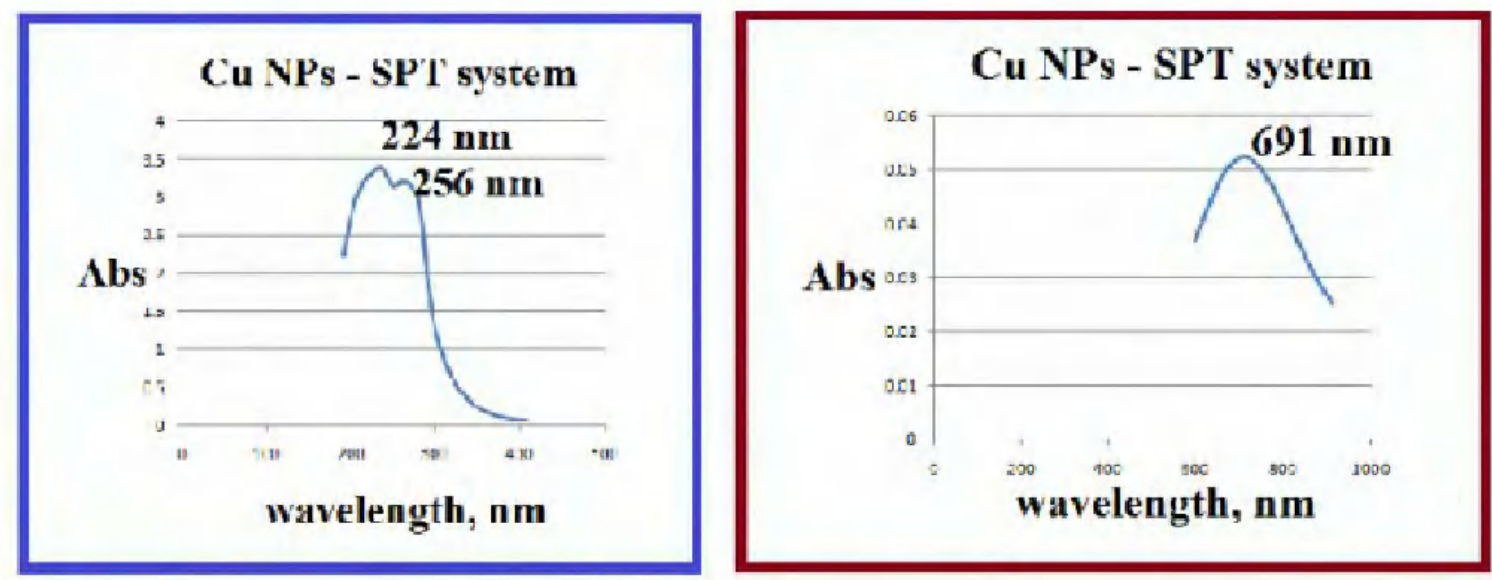

Figure 32. UV-visible absorption spectrum of CuNPs (SPT system).

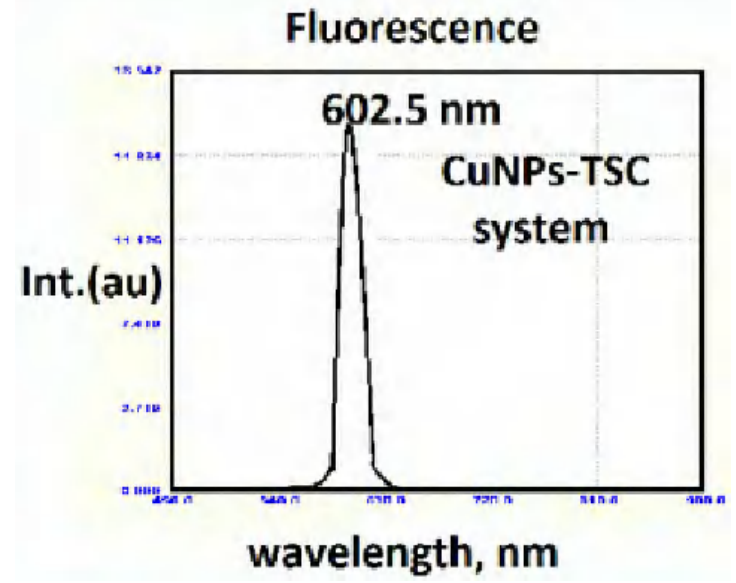

Figure 33. Emission spectrum of CuNPs (TCS system).

The slight shifts in the position of peaks may be due to the size of the nanoparticles. The CuNPs are found to be UV- fluorescent $\left(\lambda_{\text {ex }}\right)=300 \mathrm{~nm}$ (Figs. $33,34)$. 


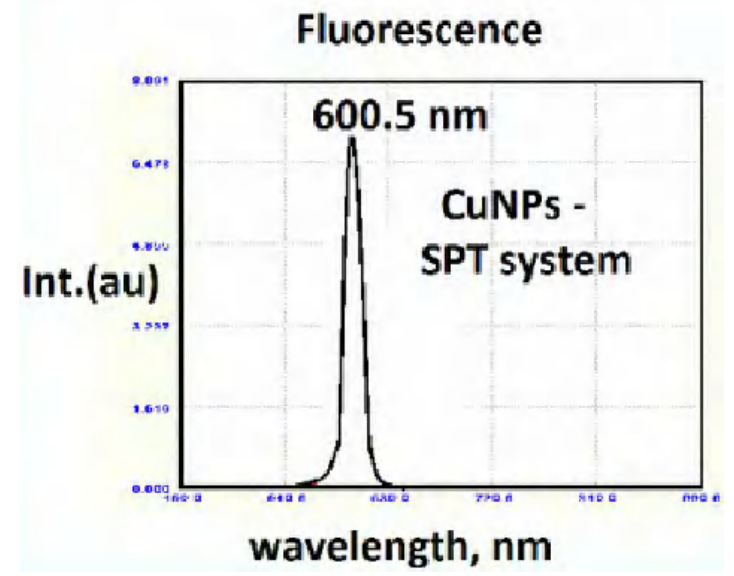

Figure 34. Emission spectrum of CuNPs (SPT system).

\section{Electrochemical Hofmann rearrangement}

Hofmann rearrangement involves conversion of acid amide into primary amine in the presence of hypohalite $\mathrm{OCl}^{-}, \mathrm{OBr}^{-}\left(\mathrm{Cl}_{2} / \mathrm{NaOH}, \mathrm{Br}_{2} / \mathrm{NaOH}\right)$. In the present study benzamide was converted into a primary amine. $1 \mathrm{~g}$ of benzamide was taken as an undivided cell containing an aqueous solution of $5 \% \mathrm{NaCl}$ solution. The anode was platinised titanium. The cathode was graphite (Fig. 35).

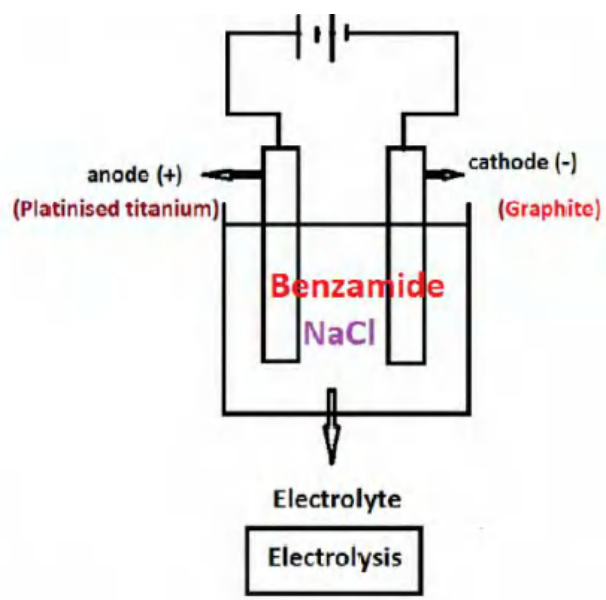

Figure 35. Electrochemical Hoffman rearrangement (block diagram).

A potential difference of 6 volts was applied for 5 minutes. The current density was $50 \mathrm{~mA} / \mathrm{cm}^{2}$. During electrolysis of $\mathrm{NaCl}, \mathrm{Cl}_{2}$ and $\mathrm{NaOH}$ are produced. Thus, hypochlorite is produced. This has produced the Hofmann rearrangement climate. The resulting primary amine was diazotised and coupled with alkaline $\alpha$ naphthol in $\mathrm{NaOH}$ solution, and $\beta$-napthol in $\mathrm{NaOH}$ solution. Dyes were produced. These dyes were matched with the dyes prepared from pure aniline. 


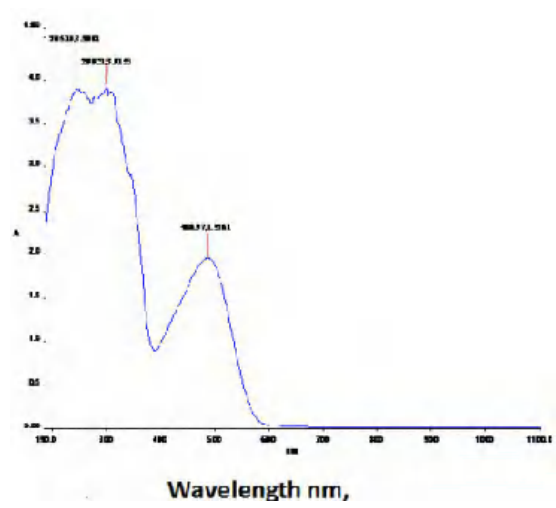

Figure 36. UV-visible absorption spectrum of aniline-alpha naphthol.

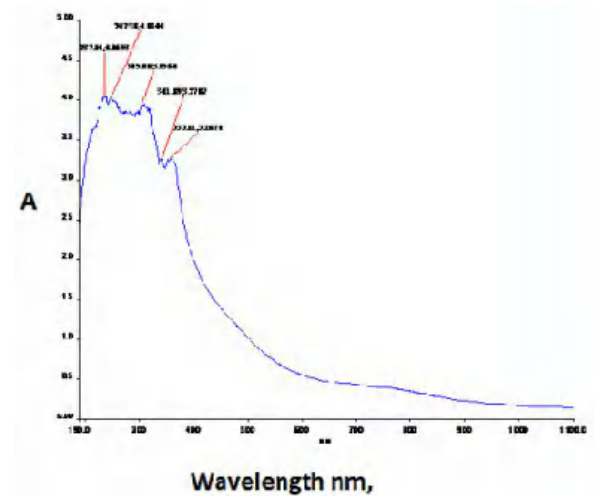

Figure 37. UV-visible absorption spectrum of aniline-alpha naphthol dye.

The UV-visible adsorption spectra of the respective dyes were compared (Figs. 36 and $37 ; 38$ and 39 ).

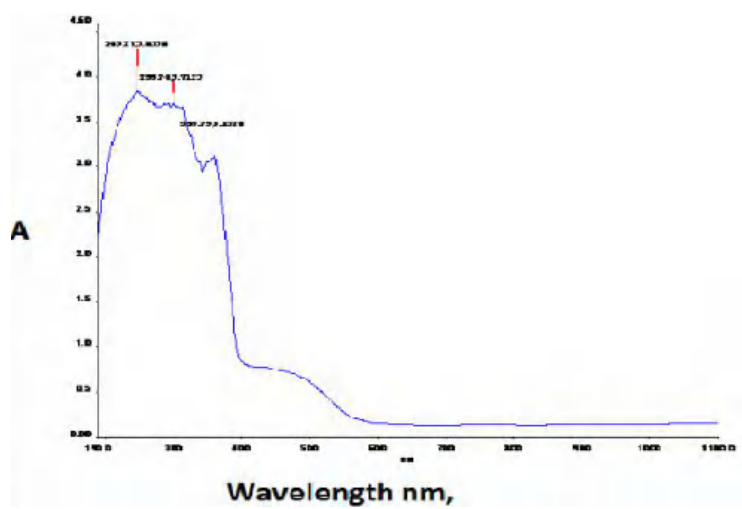

Figure 38. UV-visible absorption spectrum of aniline-beta naphthol dye.

It is observed that, in the case of dyes obtained from pure aniline, a peak occurred around $475 \mathrm{~nm}$ range. But these peaks are absent or insignificant in the case of the spectra of dyes prepared by electrochemical method. 


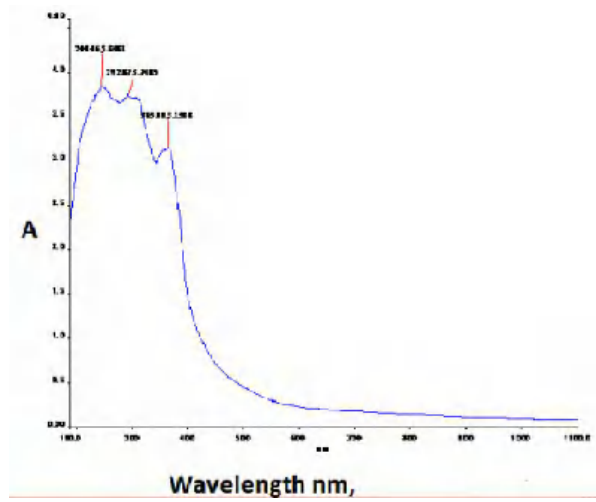

Figure 39. UV-visible absorption spectrum of beta naphthol dye.

This may be due to the fact that the dyes prepared by electrochemical method are polymeric in nature (Figs. 40 and 41).

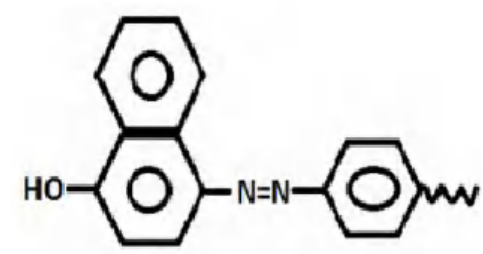

Figure 40. Probable structure of alpha naphthol dye.

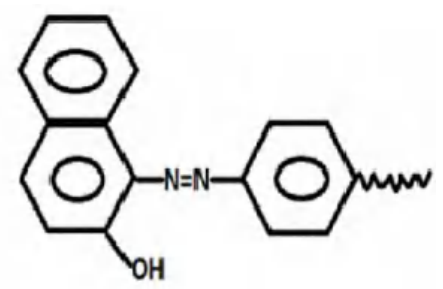

Figure 41. Probable structure of beta naphthol dye.

Further study in this line will lead to interesting conclusions. The dyes prepared from pure aniline and the dyes prepared by electrochemical method are found to be UV- fluorescent. (Figs. 42 and 43; 44 and 45).

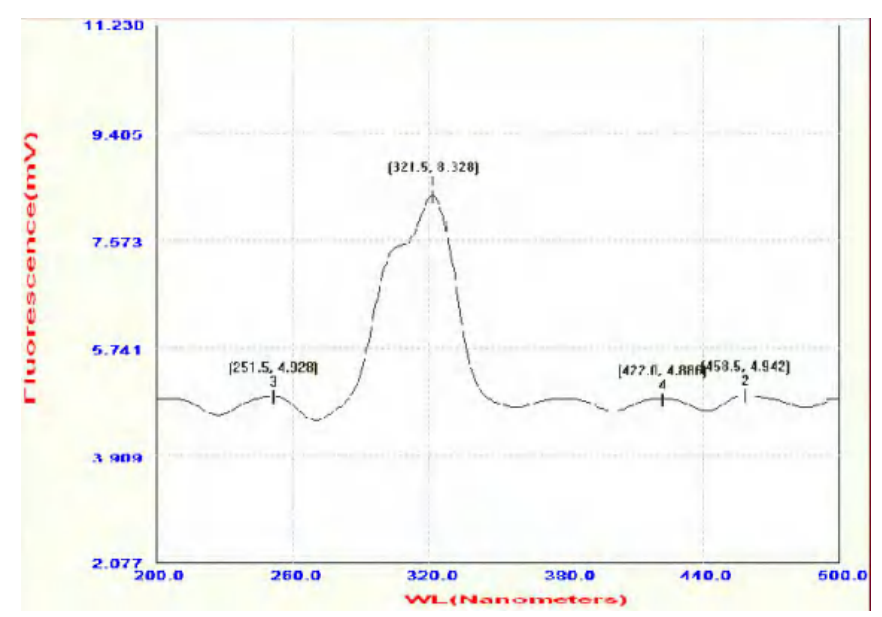

Figure 42. Emission spectrum of aniline-alpha naphthol dye. 


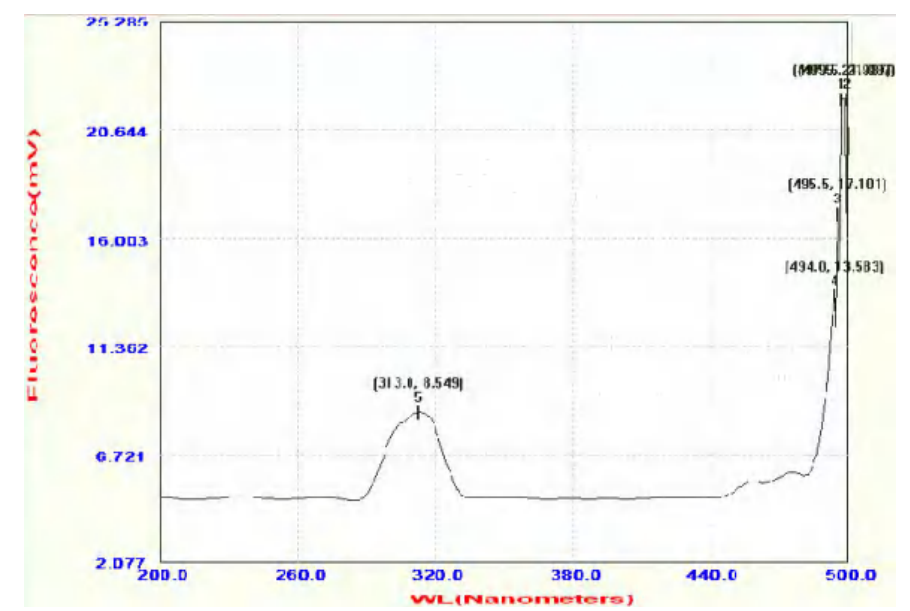

Figure 43. Emission spectrum of alpha naphthol dye.

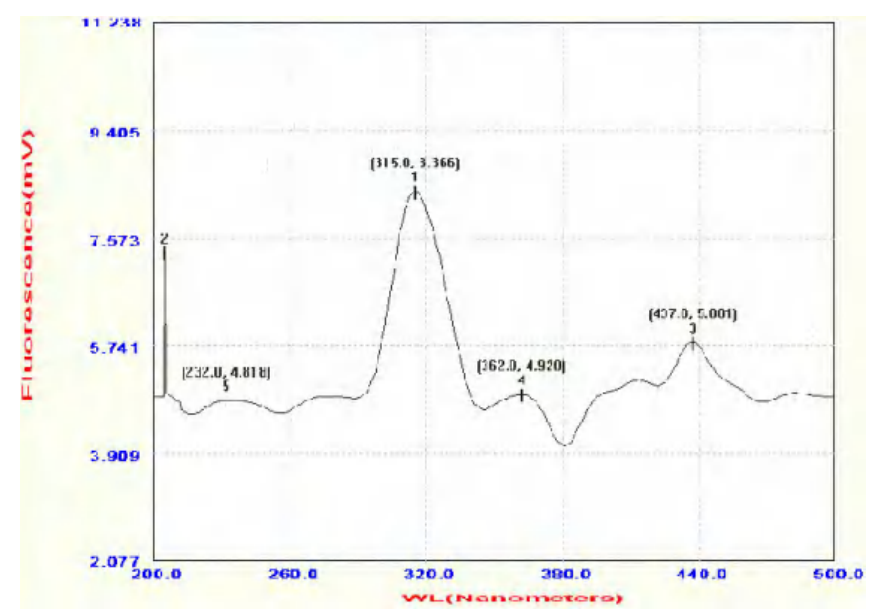

Figure 44. Emission spectrum of aniline-beta naphthol dye.

\section{Electrochemical synthesis of poly aniline (PANI)}

Aniline hydrochloride was dissolved in water and diluted to $100 \mathrm{~mL}(\mathrm{pH}=0.5) .5$ $\mathrm{g}$ of $\mathrm{NaCl}$ were added. The solution was electrolysed (Fig. 46) using platinised titanium, and graphite cathode for a period of 5 minutes.

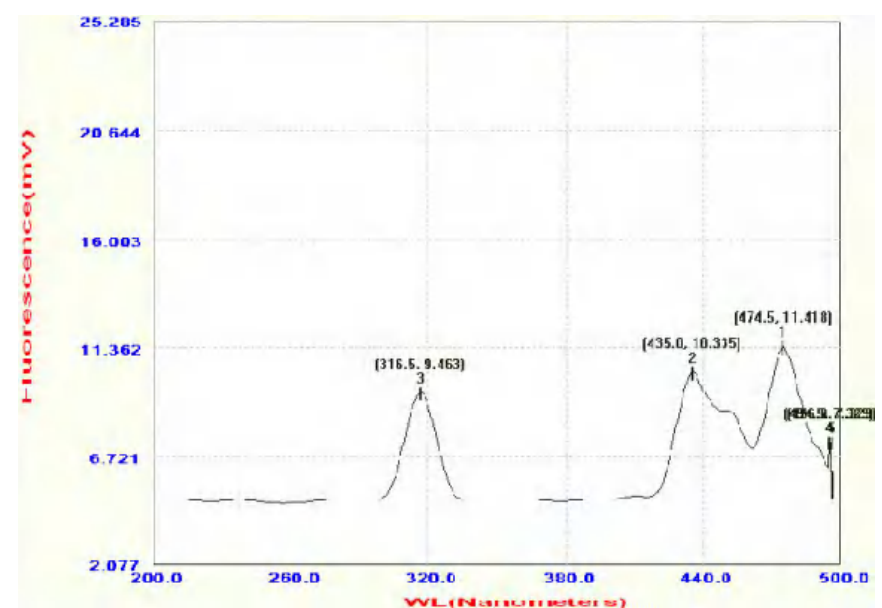

Figure 45. Emission spectrum of beta naphthol dye. 


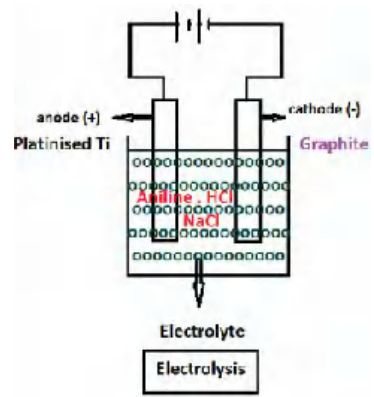

Figure 46. Electrochemical synthesis of polyaniline (block diagram).

A potential difference of 6 volts was applied. The current density was 50 $\mathrm{mA} / \mathrm{cm}^{2}$. Emerald green poly aniline was produced. In this method, conventional oxidizing agents were not used. The positive chloride ions produced in situ acted as oxidizing agent and initiated the polymerization process.

The UV-visible absorption spectrum of polyaniline produced showed peaks at $289 \mathrm{~nm}$ and $461 \mathrm{~nm}$ (Figs. 47 and 48).

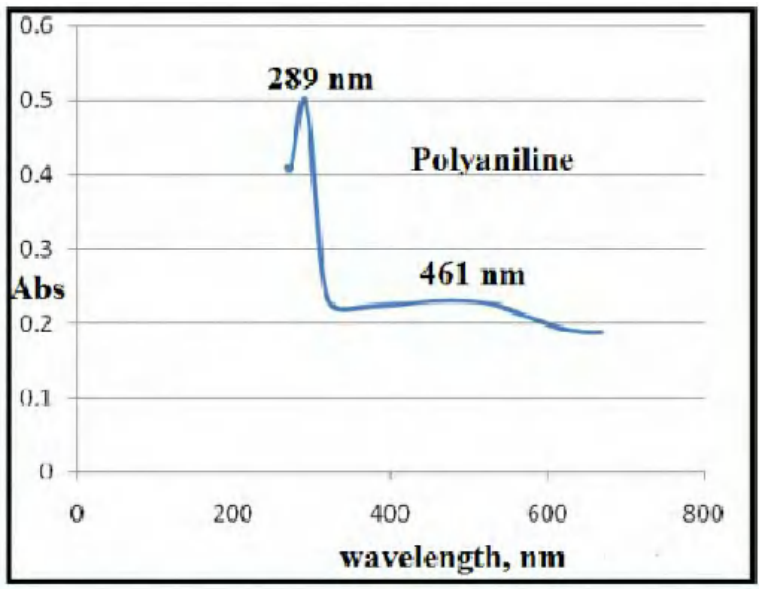

Figure 47. UV-visible absorption spectrum of polyaniline.

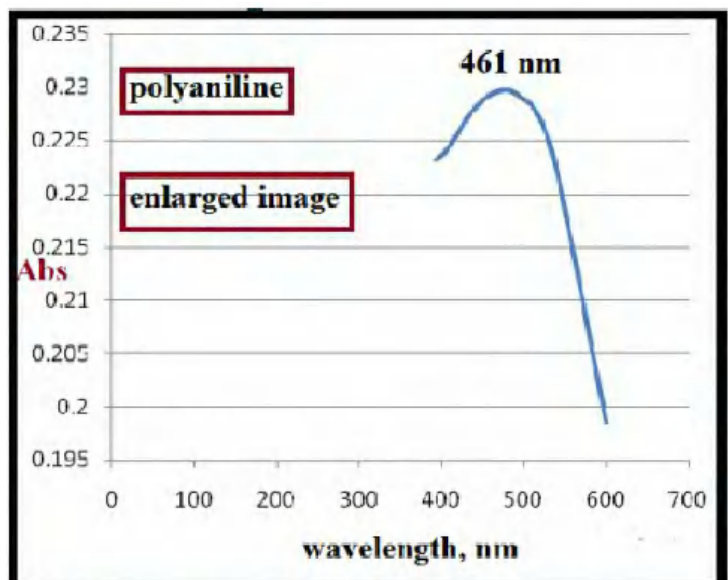

Figure 48. UV-visible absorption spectrum of polyaniline (enlarged image).

\section{FTIR spectra of polyaniline}

The main poly aniline structure is shown in Fig. 49. 


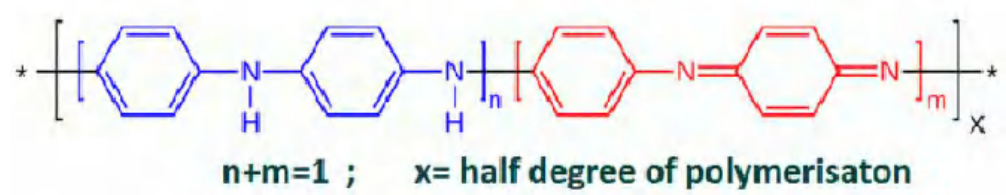

Figure 49. Main polyaniline structure.

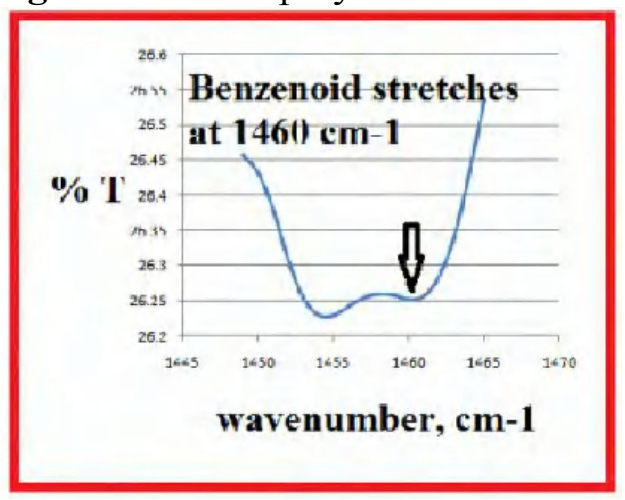

Figure 50. FTIR spectrum of PANI benzenoid stretches.

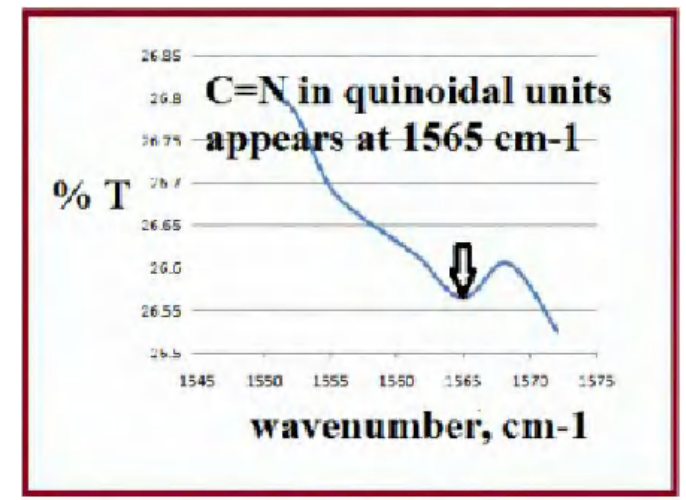

Figure 51. FTIR spectrum of PANI. $\mathrm{C}=\mathrm{N}$ in quinoidal units.

The FTIR spectra $(\mathrm{KBr})$ of the poly aniline produced confirm the presence of benzenoid stretches (Fig.50), $\mathrm{C}=\mathrm{N}$ quinoidal units (Fig. 51) and $-\mathrm{NH}$ stretches (Fig.52). Thus, electrochemically generated poly aniline is confirmed.

\section{NH-stretches at $3420 \mathrm{~cm}-1$}

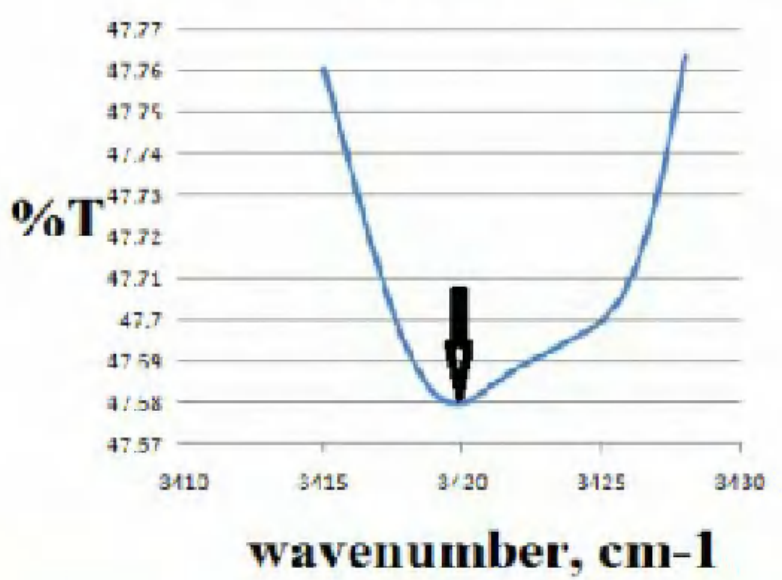

Figure 52. FTIR spectrum of PANI NH- stretches. 


\section{Electrochemical green synthesis}

By electrochemical method, dyes have been decolourised. Blue pigment has been produced. Silver and copper nano particles have been synthesized. Hofmann rearrangement has been effected. Poly aniline has been synthesized. All these processes use less hazardous chemicals. Safe chemicals and products are involved. Water is used as a solvent. There is no heating. Reaction time is only 5 minutes. Efficiency can be improved by increasing the voltage. Electric energy can be used again and again. Side products are not obtained. The $\mathrm{Cl}^{+}$is used as catalyst and reagent. It is continuously generated. The products can be easily degraded. The experiments are free from pollution. The reactions can be started and stopped anytime.

All these facts support electro synthesis as a versatile green technique of the future.

\section{Acknowledgements}

The authors are thankful to their managements and Management of SRM Universty, Chennai, India, which is responsible for initiating this paper.

\section{References}

1. Rajendran S, Trivedi DC. Synthesis Feb. 1995;153.

2. Chhabra M, Mishra S, Sreekrishnan TR. Biochem Eng J. 2015;93:17-24.

3. Pramila M, Manikandan S, Anju KS, et al. Sep Purif Technol. 2014;132:719-727.

4. $\quad$ Lin H, Zhang H, Hou L. J Hazardous Mater. 2014;276:182-191.

5. Joany RM, Shanthy P, Mary ACC, et al. Int J Nano Corr Sci Eng. 2015;2:16.

6. Howard JW, Derick CG. J Am Chem Soc. 1924;46:166-177.

7. Vivekanandan J, Ponnusamy V, Mahudeswaran A, et al. Arch Appl Sci Research. 2011;3:147-153.

8. Rajendran S, Devi MK, Regis APP, et al. Zastita Materijala. 2009;50:131140.

9. Sathiyabama J, Rajendran S, Selvi JA, et al. Bull Electrochem. 2006;22:363-369.

10. Gowri S, Bama JS, Rajendran S, et al. Int J Nano Corr Sci Eng. 2014;1:2430. 